\title{
UAV for 3D Morphological Mapping Applications: A Case Study of Koru Mining Site, Canakkale, NW Turkey
}

\author{
Oya ERENOGLU
}

\begin{abstract}
The use of UAV has steadily increased over the past decade, and it has been seen as a standard research tool for obtaining images and other information on demand. Nowadays, UAV platforms are a valuable source of data for inspection, surveillance, mapping and 3D modelling problems for earth sciences, especially in all engineering and technical fields. New applications have been introduced for the short-and close-range domain in mining sites, UAVs are a low-cost alternative to classical manned aerial photogrammetry to generate detailed 3D models and orthophoto. In this paper, a workflow of UAV photogrammetry with the use of a widely accessible digital camera was employed, for 3D reconstruction and feature extraction of a mining site. In addition, a detailed accuracy assessment for the products using low-cost UAV was performed for 3D morphological modelling and feature extraction. The obtained results are illustrated in detail on the examples. Their comparison with the results of the conventional surveying systems was provided.
\end{abstract}

Keywords: accuracy assessment; geomorphology; orthophoto; photogrammetry; structure frommotion; UAV

\section{INTRODUCTION}

Unmanned Aerial Vehicles (UAVs) are an important part of the pilotless airborne systems controlled by ground control stations and the entire system required for the carrier platform to fly [1]. These systems were not only developed primarily for military applications, but civil applications of UAVs have also gained wide popularity in collecting geometric and structural data, with enormous advances in technology over the years [2-4]. For example, the current enhancements in hardware and software technology provide opportunities for applications in a variety of science fields [5-11]. Naturally, the possible field of activity of these systems has expanded steadily such as archaeological modelling [12-14], farming applications [15], monitoring of natural hazards $[16,17]$ and accurate geomorphologic mapping [18-20].

It is very important to model structures and to extract the features for geological applications [21]. Many methods have been developed to cope with this problem such as terrestrial surveys, GPS/GNSS technique, close range and aerial photogrammetry and satellite images [22]. Moreover, the Unmanned Aerial Systems (UAS) technology is commonly preferred for different applications because of its pilotless carrier platform. Although Digital Elevation Models (DEMs) can be derived by conventional photogrammetry approaches, it requires aerial photographs or stereo pairs, specialist software, expertise, and extensive manual measurement of control points or features [23].

This paper focuses on the application of Unmanned Aerial System (UAS) photogrammetry for the purposes of the creation of $3 \mathrm{D}$ reconstruction and feature extraction of the mining area with the use of a widely accessible digital camera. For this purpose, a case study was completed in the Koru Mining Area, Canakkale (NW Turkey). In particular, data from a UAV photogrammetric survey was used to obtain 3D Digital surface models from processed UAV images for the feature extraction in geological applications. The generation of the high accurate DEM is crucial for estimating the geometrical shape of mining area and for extracting mineralization and possible alterations. Using the final products from UAV photogrammetry and
GPS/GNSS surveys, a detailed comparison for accuracy analysis is performed. To achieve the following workflow, this was to design and to develop a UAS system: (a) Designing the UAS system for geological applications, (b) Calibrating all the sensors, (c) Connecting and geo-sensors such as GPS/GNSS, gyrocompass, pivoting mouth and digital camera, (d) GPS/GNSS surveying for Ground Control Points (GCPs), (e) Testing the systems in a flight experiment, (f) Processing data, 3D modelling, analysing and comparing the results for the applications.

\section{METHODOLOGY}

Several photogrammetric and geodetic methods have been employed to generate 3D realistic models for geological applications. In this study, overlapped aerial photos are taken using digital camera on the UAV in the direction of flight as indicated in the workflow in Fig. 1. This workflow provides the real operation process of UAV photogrammetry with digital camera to show the field practicability of the technology.

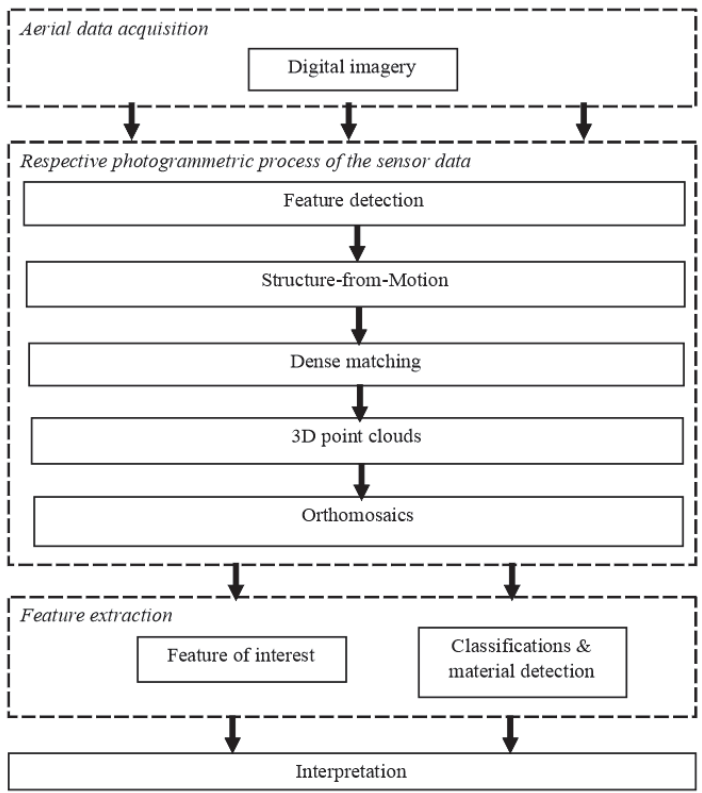

Figure 1 The workflow of the image acquisition and processing 


\subsection{Eight-Rotor Oktokopter UAV}

Among the UAV technologies that are widely used in the market today, open source systems are generally more efficient and cost-effective. If a comparison is made with conventional single rotor helicopters, it is clear that multirotor systems are quite stable, especially during flight and data collection, and do not require a very complex rotor structure. In the multi-rotor system developed and used within the scope of this study, it has an inertial measurement unit (IMU) that can measure acceleration, gyroscope, compass and pressure in three axis directions respectively. The stability of the device during flight is ensured with the help of this advanced hardware system. As a result, a multi-rotor open source project has been implemented by integrating the necessary additional software and electronic hardware to be used effectively in earth sciences and especially in geological studies [24] (Fig. 2).

The technical specifications of this aerial vehicle are as follows: The dimensions of the device are $73 \mathrm{~cm}, 73 \mathrm{~cm}$ and $36 \mathrm{~cm}$ in width, length and height, respectively. The maximum safe payload is specified as $2.5 \mathrm{~kg}$. With this weight and fully charged battery, the flight time is estimated to be 45 minutes by the manufacturer, but in our experience the realistic flight time is 18 to 28 minutes. The maximum height and horizontal distance the device can reach is a few hundred meters. In addition, instantaneous voltage meter, capacitance meter, current meter, height, distance, speed and motor temperature information are among the other technical features included in the device.

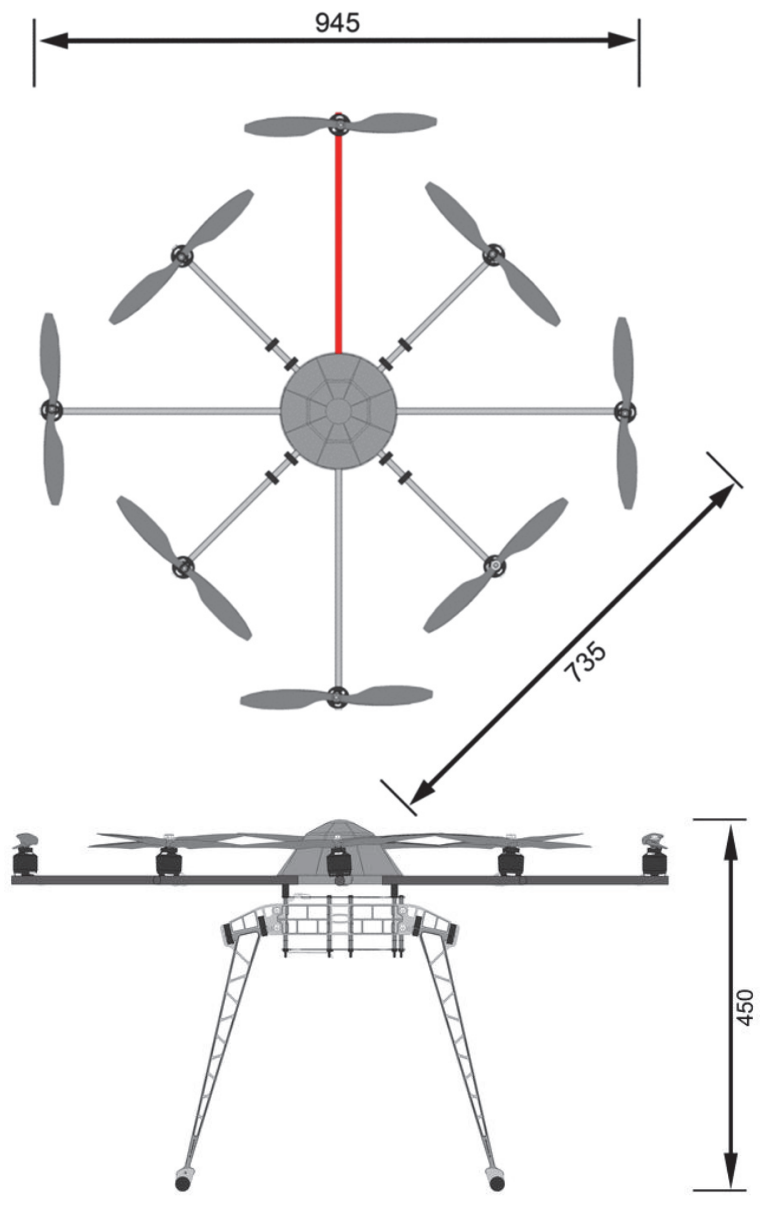

Figure 2 Top and side view of the UAV Oktokopter XL

\subsection{Camera Systems}

In this study, it was decided to use an ultra-light and high-capacity digital camera that can work with the devices in order to achieve the maximum flight time specified by the manufacturer. For this purpose, the Canon EOS-M digital camera was integrated into the drone in order to take high resolution aerial photographs (Fig. 3). During the flights carried out within the scope of the study, the camera focal length was determined as $18 \mathrm{~mm}$. In addition, in order to prevent blurring of photographs, the average shutter speed was realized as $1 / 800$ second.
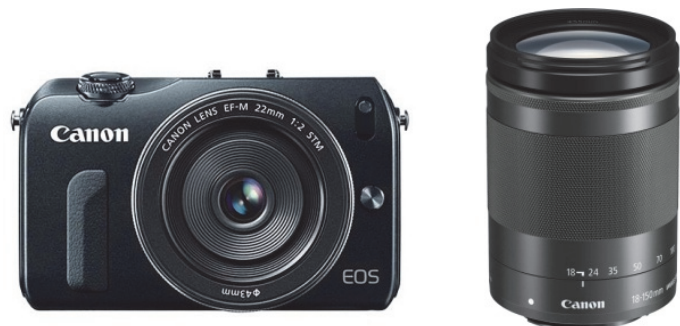

Figure 3 Canon EOS M Mirrorless Digital Camera with 18-55mm Lens

\subsection{Camera Calibration}

As with all other measuring equipment, camera calibration improves the accuracy of the resulting products from subsequent application projects. In the general photogrammetric approach, the current parameters of the camera are calculated with the help of camera calibration. The data file containing parameters such as focal length, format aspect ratio, coordinates of principle point and lens distortion determined from the calibration process is created for use in future projects. In other words, camera calibration is indispensable, especially in order to obtain high accuracy results. There are many calibration approaches that have been developed and improved for this purpose. In particular, some software packages of photogrammetric processing offer fully automated camera calibration schemes that provide high accuracy results, without any additional payment. For the calibration of the digital camera used in this study, the camera calibrator of the PhotoModeler software developed with the abovementioned approach was used. A series of photographs were taken from all four sides of the grid pattern placed on the ground, using a tripod-supported digital camera to ensure image stability. Fig. 4 shows the grid pattern on the floor. Then, the calibration process was performed using the camera calibrator of the PhotoModeler software and the updated calibration report was finally produced.

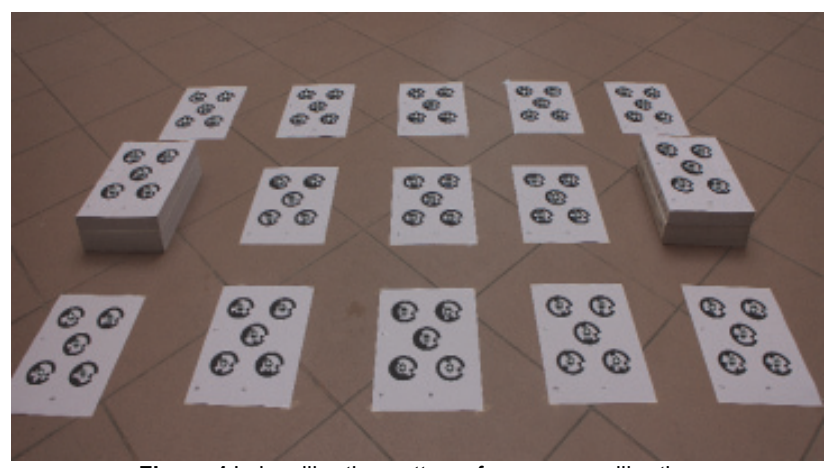

Figure 4 Lab calibration patterns for camera calibration 


\section{STUDY AREA AND DATA ACQUISITION}

The study area is in the northeast part of CanakkaleBiga Peninsula, NW Turkey (Fig. 5). The Koru mining site covers approximately an area of $11 \mathrm{~km}^{2}$. The main reason for the selection of this study area is that it contains different geological units and alterations on a macro scale and also has difficulties in field studies due to steep terrain. The geology of the Koru Mining Site consists of Eocene andesitic lava, agglomerate and tuffs, Oligocene-Miocene tuffs and Miocene rhyolitic lavas. Usually, rhyolitic volcanics show dome structure. The youngest unit of alluvium in the study area. This lavas array direction is NW-SE. Pb-Zn-Ag mineralization is hosted in rhyolitic domes and rhyolite-tuff contact. Locally, mineralization in the tuff is fault controlled and has no economic significance. The relationship to rhyolitic mineralization is big dimension and high grade in the NWSE zone and it is composed of galenite, sphalerite and coarse-grained barites. The area lies to the north of $8 \mathrm{~m}$. wide vein. These are followed by highly brecciated siliceous rocks. In a fault zone around Koru Mining Site, a pyrite-chalcopyritevein is located [25]. The age of tuffs and andesites associated with mineralizations in the Koru area is accepted as post-Eocene. The veins in the tuffs generally contain sphalerite, galenite, pyrite, chalcopyrite, barite, calcite, quartz and secondary copper enrichments [26]. In addition, it is stated that the volcanism in the area is Oligocene or Miocene and formed in marine environment and therefore approximately $300 \mathrm{~m}$ thick tuff is deposited [27].

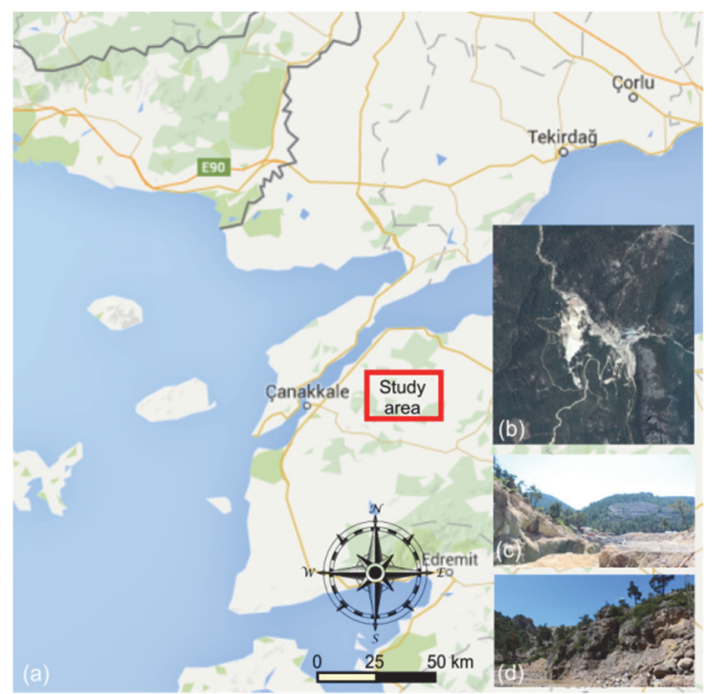

Figure 5 (a) The localization of the study area (GPS $40^{\circ} 13^{\prime} 25^{\prime \prime} \mathrm{N}, 26^{\circ} 44^{\prime} 50^{\prime \prime} \mathrm{E}$ ); (b) Satellite imagery of the Koru Mining Site; (c) A snapshot in a N-S direction; (d) A snapshot in E-W direction

On February $20^{\text {th }}$ and $22^{\text {nd }} 2018$, aerial photographs were taken based on the flight plan covering the entire study area to derive geological structure data. The system runs in horizontal directions using the moving camera mount. Two people operated the autonomous UAV flight, e.g. groundstation and operator. The flight operator is primarily responsible for the equipment not being damaged during landing, take-off and flight. Ground station performed to monitor flight info between UAV and computer, number of satellite, real time battery status,
UAV position and attitude at the ground station. In the flight planning, the most suitable take-off and landing places for flight are determined in the study area. The flight planning included 30 predefined waypoints in Google KML formats. Lateral photographs were taken to produce models of steep slopes and cliffs.

During the flight, aerial photographs were taken manually by the shooter on the remote control of the ground crew. The aircraft was taken to a height of 20 meters right after take-off. It was held in this position for about 30 seconds. 420 aerial photographs were taken on the first flight date. Immediately after the flight, the photographs taken were downloaded to the computer and it was checked whether the entire working area was scanned.

\section{DIGITAL SURFACE MODEL PROCESSING}

In order to create digital surface model of the Koru Mining Site, the obtained data were processed using Agisoft Photoscan software. Note that two sets of the data were evaluated with the same approach of image processing as in Fig. 1 and the photogrammetric products were obtained. Although the geomorphologic models are statistically identical in results, only the results of the first data collection date are presented here due to the lack of space. The aerial photographs of the mining area were processed to obtain digital surface models and to extract the geological features in three working areas. In the first stage of photogrammetric processing, all collected photos are processed to obtain point cloud and dense cloud, see Figs. $6 \mathrm{a}$ and $6 \mathrm{~b}$. Then, a dense cloud classes are computed using the patch approach of multi-view stereo dataset (Fig. $6 c)$. Finally, the shaded model is successfully created as given in Fig. 6d.

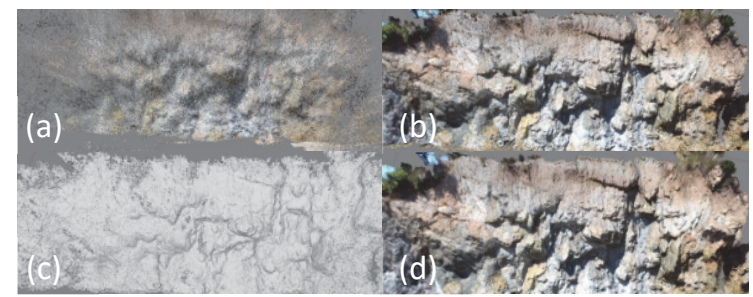

Figure 6 (a) Point cloud from UAV photos; (b)Dense cloud; (c)Dense cloud classes; (d)Shaded model

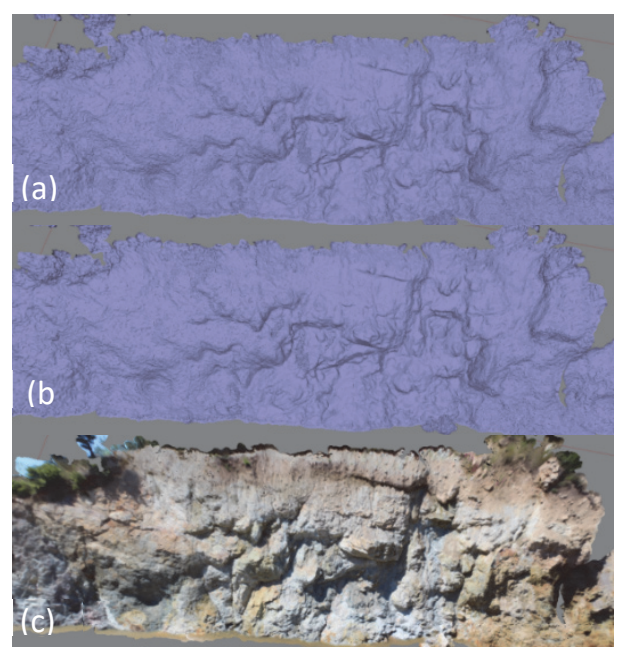

Figure 7 (a) Image frustum plane; (b) Point cloud with single color; (c) Point cloud with exact color from photo 
As the last step, the 3D solid and wireframe models of the working area were obtained as seen in Figs. 7a and 7b, respectively. The textured digital surface model with exact colour was generated in Fig. 7c.

\section{GEOMETRICAL ACCURACY OF THE PRODUCED 3D MODELS}

There are many studies where a high resolution photogrammetric product has been successfully obtained by processing aerial photographs using Structure from Motion (SfM) algorithms [28, 29]. Detailed information on photogrammetric sub-products is also provided in the previous sections. Here, the accuracy analyses of the threedimensional models were performed using RTK/GNSS and CORS measurements as well as the coordinates of the generated model. In order to do it, we used 30 ground control points that were surveyed before. Univariate statistics of the point cloud were studied in order to find out the statistical properties of the obtained data. Each coordinate component was taken as a separate data point. Tab. 1 shows some univariate statistics of the point cloud. Furthermore, the quantiles were calculated for the cumulative probabilities of $0.25,0.5,0.75$, and 0.975 [30]. The autocorrelation procedure of the PhotoModeler Scanner provided a well distributed data due to normal distributed point positions of data cloud.

Table 1 Univariate statistics of the point cloud
\begin{tabular}{|c|c|c|c|}
\hline Quantity & $X / \mathrm{m}$ & $Y / \mathrm{m}$ & $Z / \mathrm{m}$ \\
\hline Min. & 4452424.418 & 478550.372 & 170.934 \\
\hline Max. & 4452583.816 & 478798.928 & 202.414 \\
\hline Mean & 4452381.131 & 478716.969 & 208.756 \\
\hline Median & 4452461.316 & 478585.628 & 209.766 \\
\hline
\end{tabular}

The errors in the coordinates between 3D model and RTK/GNSS are given in Tab. 2. As can be easily seen, the errors in $X$ and $Y$ components are in centimetre level. The coordinates of the 3D model are in accordance with the coordinates surveyed by RTK/GNSS. In the UAV photogrammetry, the flight height was limited to 20 meters in this study to eliminate the measurement error caused by poor vision, especially when shooting at high altitudes. As can be seen in Tab. 2, the surveyed errors are mostly at the centimetre level, which is the clear result of limiting the problem of poor vision which can be caused by high altitudes.

Table 2 The surveyed errors between UAS- orthophoto and RTK/GNSS for the GCPs

\begin{tabular}{|c|c|c|c|c|c|}
\hline GCP \# & $\begin{array}{c}\text { Error in } X Y / \\
\mathrm{m}\end{array}$ & $\begin{array}{c}\text { Error in } Z / \\
\mathrm{m}\end{array}$ & GCP \# & $\begin{array}{c}\text { Error in } X Y \\
/ \mathrm{m}\end{array}$ & $\begin{array}{c}\text { Error in } Z / \\
\mathrm{m}\end{array}$ \\
\hline 1 & 0.015 & -0.037 & 9 & 0.017 & 0.034 \\
\hline 2 & 0.034 & 0.049 & 10 & 0.012 & -0.042 \\
\hline 3 & 0.032 & 0.036 & 11 & 0.035 & 0.058 \\
\hline 4 & 0.024 & -0.037 & 12 & 0.021 & -0.031 \\
\hline 5 & 0.020 & 0.028 & 13 & 0.031 & 0.039 \\
\hline 6 & 0.036 & -0.030 & 14 & 0.029 & -0.055 \\
\hline 7 & 0.033 & 0.048 & 15 & 0.020 & -0.029 \\
\hline 8 & 0.026 & 0.060 & 16 & 0.032 & 0.059 \\
\hline
\end{tabular}

The $X, Y$ and $Z$ coordinate components from UASOrthophoto and RTK/GNSS surveys were given in Tabs. 3 and 4, respectively. More importantly, a similar feature can be seen in the differences between coordinates. We also focused on the mean and standard deviations of the errors for a detailed comparison between the 3D photogrammetric model and GNSS measurements. Averages of differences between RTK/GNSS and CORS measurements, and photogrammetric model errors are -5.1 $\mathrm{mm}$ and $-5.6 \mathrm{~mm}$ for the $X$ coordinates; $-4.2 \mathrm{~mm}$ and -5.3 $\mathrm{mm}$ for the $Y$ coordinates, respectively. On the other hand, when the standard deviations between the 3D photogrametric model and the GNSS measurements are calculated, the standard deviations of the errors between RTK/GNSS and CORS measurements, and photogrammetric model are $0.0218 \mathrm{~m}$ and $0.0267 \mathrm{~m}$ for the $X$ coordinates; $0.0235 \mathrm{~m}$ and $0.0242 \mathrm{~m}$ for the $\mathrm{y}$ coordinates, respectively. If the results of the CORS measurements are analyzed, it is concluded that the standard deviations are greater than the RTK/GNSS. This can be interpreted as the selected RTK/GNSS reference station is very close to the area of study compared to CORS stations. Of course, this is a case-specific situation.

Table 3 The UAS-orthophoto coordinates of check points

Table 3 The UAS-orthophoto coordinates of check points
\begin{tabular}{|c|c|c|c|}
\hline \multirow{2}{*}{$\begin{array}{c}\text { Check } \\
\text { Point \# }\end{array}$} & \multicolumn{3}{|c|}{ UAS - Orthophoto Coordinates } \\
\cline { 2 - 4 } & $X / \mathrm{m}$ & $Y / \mathrm{m}$ & $Z / \mathrm{m}$ \\
\hline C1 & 4452543.645 & 478735.180 & 187.121 \\
\hline C2 & 4452570.160 & 478685.394 & 194.049 \\
\hline C3 & 4452540.516 & 478622.878 & 178.976 \\
\hline C4 & 4452500.787 & 478759.498 & 180.671 \\
\hline C5 & 4452576.526 & 478789.346 & 200.661 \\
\hline C6 & 4452576.860 & 478760.584 & 197.914 \\
\hline C7 & 4452503.556 & 478667.595 & 179.600 \\
\hline C8 & 4452446.763 & 478753.787 & 173.689 \\
\hline C9 & 4452432.381 & 478707.021 & 174.472 \\
\hline C10 & 4452481.758 & 478632.760 & 179.021 \\
\hline C11 & 4452529.893 & 478648.456 & 178.610 \\
\hline C12 & 4452492.349 & 478571.337 & 190.031 \\
\hline C13 & 4452542.774 & 478555.602 & 180.649 \\
\hline
\end{tabular}

Table 4 The RTK/GNSS coordinates of check points

\begin{tabular}{|c|c|c|c|}
\hline \multirow{2}{*}{$\begin{array}{c}\text { Check } \\
\text { Point \# }\end{array}$} & \multicolumn{3}{|c|}{ RTK/GNSS Coordinates } \\
\cline { 2 - 4 } & $X / \mathrm{m}$ & $Y / \mathrm{m}$ & $Z / \mathrm{m}$ \\
\hline C1 & 4452543.628 & 478735.185 & 187.109 \\
\hline C2 & 4452570.166 & 478685.401 & 194.078 \\
\hline C3 & 4452540.531 & 478622.856 & 179.007 \\
\hline C4 & 4452500.777 & 478759.497 & 180.665 \\
\hline C5 & 4452576.526 & 478789.360 & 200.684 \\
\hline C6 & 4452576.870 & 478760.599 & 197.875 \\
\hline C7 & 4452503.557 & 478667.572 & 179.605 \\
\hline C8 & 4452446.789 & 478753.761 & 173.648 \\
\hline C9 & 4452432.366 & 478706.999 & 174.491 \\
\hline C10 & 4452481.771 & 478632.777 & 179.019 \\
\hline C11 & 4452529.902 & 478648.459 & 178.594 \\
\hline C12 & 4452492.331 & 478571.340 & 189.986 \\
\hline C13 & 4452542.786 & 478555.598 & 180.624 \\
\hline
\end{tabular}

\section{ANALYSIS AND FEATURE EXTRACTION}

In the study area, the rocks and altered samples are from the three different zones, i.e. sub-areas \#1, \#2 and \#3. These samples are rhyolitic lava, agglomerate, sulphuric alteration from sub area \#1, agglomerate, rhyolitic lava and cuprous alteration from sub area $\# 2$, sulphuric alteration, ferrous alteration and cuprous alteration from sub area \#3, respectively for the ground truth. Note that when the point cloud model is reconstructed, there may be a serious point cloud missing in some locations, which is not conducive to the recognition of feature structure. In this study, the accuracy of the geological feature structure realized with the models obtained from point clouds was checked by ground truth observations. This situation can be explained 
as a result of both the approach used in the shooting of aerial photographs and the method of obtaining photogrammetric products from these photographs. Histograms are used to evaluate a digital image obtained within the scope of this study. Histograms are available for use in data evaluation software as well as digital cameras. The regional averages of values for the actual RGB colours in the studied rock and alteration samples are obtained from the RGB histogram [31]. So, the averages of the RGB values are obtained for the rocks and altered samples. To achieve this goal, the $3 \mathrm{D}$ photogrammetric model is converted to JPG format and the images are split into three separate greyscale images showing the colour planes of the RGB by MATLAB [32] as follows:

Image_red $=$ Image_rgb(:, 1)

Image_green $=$ Image_rgb(:, 2)

Image_blue = Image_rgb(:, 3)

For each pixel in the image of the model, the following values are calculated using three components corresponding to Images_RGB matrices:

NormalizedRed $=r / \operatorname{sqrt}\left(\operatorname{Red}^{2}+\right.$ Green $^{2}+$ Blue $\left.^{2}\right)$
NormalizedGreen $=g /$ sqrt $\left(\operatorname{Red}^{2}+\right.$ Green $^{2}+$ Blue $\left.^{2}\right)$

NormalizedBlue $=b /$ sqrt $\left(\operatorname{Red}^{2}+\right.$ Green $^{2}+$ Blue $\left.^{2}\right)$

These transformations are applied to every pixel in the image. For this purpose, a colour image back is reformed, the three normalized planes to form an RGB image are restacked, and displayed. In order to save the processor's memory, the most practical way is as follows:

$$
\begin{aligned}
\text { ImagenormRGB }= & \text { cat3(NormRed,NormGreen, } \ldots \\
& \ldots \text { NormBlue })
\end{aligned}
$$

Figs. 8, 9 and 10 show the normalized 3D surface models for the sub-areas \#1,\#2 and \#3, respectively. As the final step of the study, the average RGB colours obtained for rocks and altered samples were presented in order to classify the surface properties. In this stage, the special normalization algorithm is used in order to avoid the reflecting effect by the sun. Otherwise, if a conventional normalization algorithm were used instead, the effect of density variation from rocks or altered samples would have been eliminated. At this point, the geological units and structures specified in Figs. 8, 9 and 10 were successfully identified, classified and bordered.

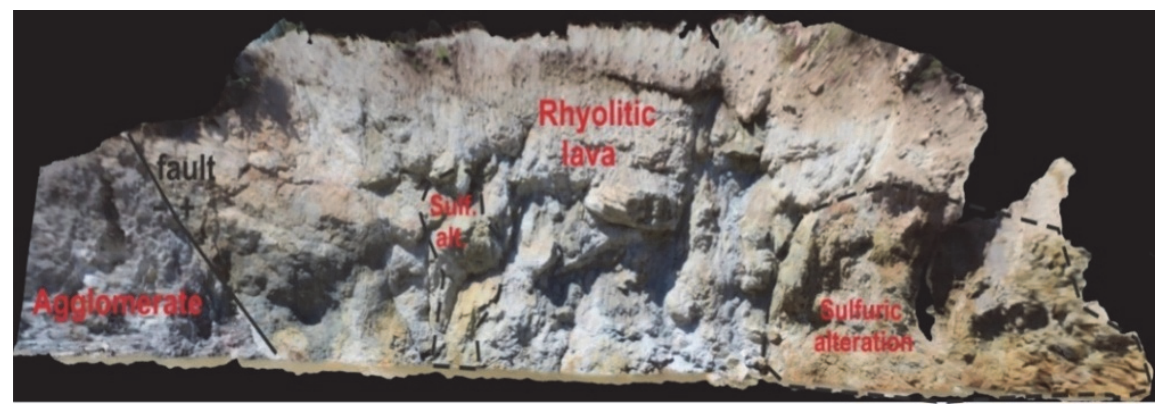

Figure 8 Rock and alteration classification in the sub area \#1

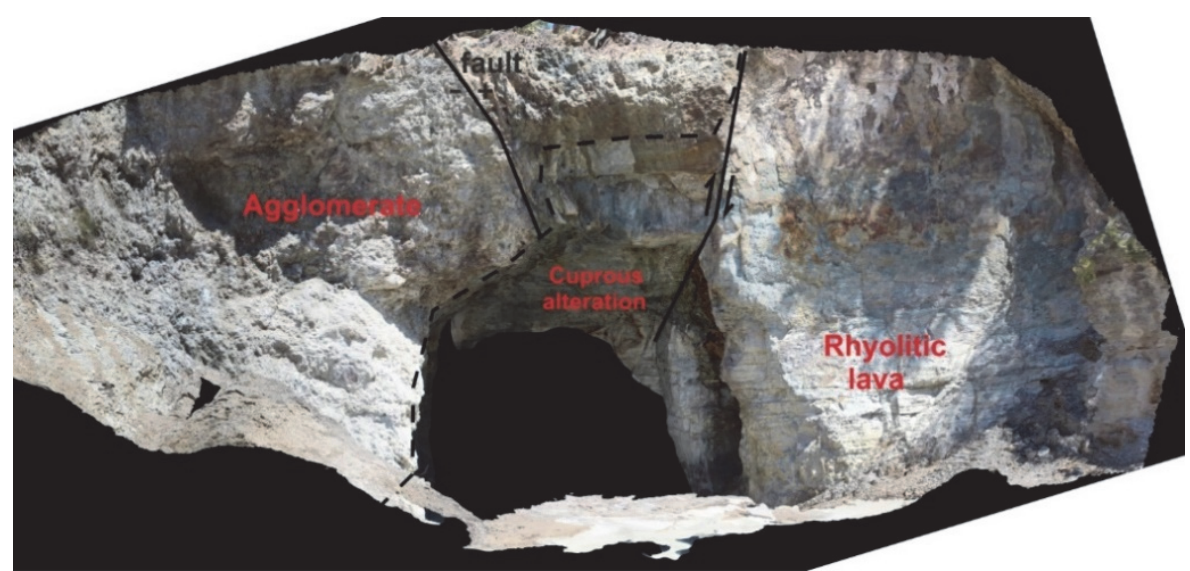

Figure 9 Rock and alteration classification in the sub area \#2

In particular, the agglomerate, rhyolitic lava and cuprous alterations at the entrance of the mine gallery seen in Fig.9 differ significantly from each other. As a highly efficient site documenting method throughout the area, UAV can reliably detect changes in approximate geological units. The limitation of the traditional approach is that it does not capture areas that are difficult to work with, especially those surfaces that the scanner station cannot reach. In this case, aerial photogrammetry can record these "hidden" and difficult to access information and complete the entire mosaic of surface geometry.
Finally, one of the outputs of photogrammetric methods is an orthophoto mosaic that provides unique information about the site. Using archive images, it has been seen that information about the site status can be obtained previously and can be used as a complement to the local geological field observations. The same result was successfully accomplished for the classification presented in Fig.10. According to the alteration classification results for the sub area \#3, sulfuric, ferrous and cuprous alterations were certainly detected and bordered using the normalized RGB approach from the UAV data. 


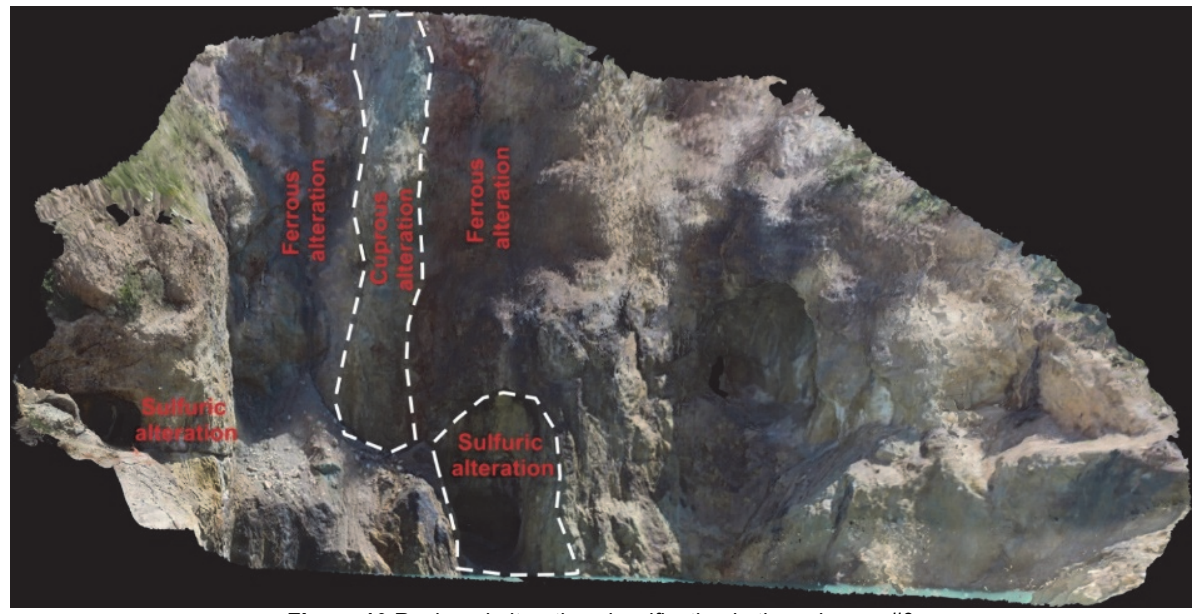

Figure 10 Rock and alteration classification in the sub area \#3

\section{CONCLUSIONS}

In this study, high-resolution UAV generated 3D models are generated to extract the rocks, associated mineralizations, alterations and fractures in the Koru Mining Site, NW Turkey. The method used in the study has enabled detailed quantitative structural analysis of open pit wall, especially inaccessible rock faces, with georeferenced 3D models up to a few centimeter level. The method is not dependent on the resolution of the working surface in shooting the multiple images in all the directions with respect to the Earth's surface for geological investigations, geometric calculations in mining sites and field characterization. The aerial photos with high resolution were processed and 3D point clouds, orthophotos and digital surface models were generated. The geological classifications were performed as rhyolitic lava, agglomerate, sulphuric alteration, ferrous alteration and cuprous alteration. Finally, the fractures and faults were also defined in the study area. The method used in this work can be used as a feasibility study to explore new mining areas, to identify different rock lithologies and mineralizations in these rocks. Future work will investigate information from all datasets of different types of sensors to better understand the relationships between 3D geomorphologic models and rock mineralization.

\section{Acknowledgements}

The author greatly appreciates the editor and two anonymous reviewers for valuable comments and suggestions, and Dr. R. Cuneyt Erenoglu for the assistance during the field surveys.

\section{REFERENCES}

[1] Hallermann, N. \& Morgenthal, G. (2014). Visual inspection strategies for large bridges using Unmanned Aerial Vehicles (UAV). 7th International Conference on Bridge Maintenance, Safety and Management (IABMAS 2014), 661667. CRC Press. https://doi.org/10.1201/b17063-96

[2] Siebert, S. \& Teizer, J. (2014). Mobile 3D mapping for surveying earthwork projects using an Unmanned Aerial Vehicle (UAV) system. Automation in Construction, 41, 114. https://doi.org/10.1016/j.autcon.2014.01.004

[3] Pajares, G. (2015). Overview and current status of remote sensing applications based on unmanned aerial vehicles
(UAVs). Photogrammetric Engineering and Remote Sensing, 81(4), 281-330.

https://doi.org/10.14358/PERS.81.4.281

[4] Zhou, S. \& Gheisari, M. (2018). Unmanned aerial system applications in construction: a systematic review. Construction Innovation, CI-02-2018-0010. https://doi.org/10.1108/Cl-02-2018-0010.

[5] Rau, J. Y., Jhan, J. P., Lo, C. F., \& Lin, Y. S. (2011). Landslide mapping using imagery acquired by a fixed-wing UAV. The International Conference on UAV in Geomatics (UAV-g). Zurich. https://doi.org/10.5194/isprsarchives-XXXVIII-1-C22-195

[6] Niethammer, U., James, M. R., Rothmund, S., Travelletti, J., \& Joswig, M. (2012). UAV-based remote sensing of the Super-Sauze landslide: Evaluation and results. Engineering Geology, 128, 2-11. https://doi.org/10.1016/j.enggeo.2011.03.012

[7] Danzi, M., Di Crescenzo, G., Ramondini, M., \& Santo, A. (2013). Use of unmanned aerial vehicles (UAVs) for photogrammetric surveys in rockfall instability studies. Rendiconti Online Societa Geologica Italiana, 24, 82-85.

[8] Salvini, R., Riccucci, S., Gullì, D., Giovannini, R., Vanneschi, C., \& Francioni, M. (2014). Geological Application of UAV Photogrammetry and Terrestrial Laser Scanning in Marble Quarrying (Apuan Alps, Italy). Sust. Planning and Landscape Exploitation, 188, 979-984. https://doi.org/10.1007/978-3-319-09048-1_188

[9] Giordan, D., Manconi, A., Facello, A., Baldo, M., Dell'Anese, F., Allasia, P., \& Dutto, F. (2015). Brief Communication: The use of an unmanned aerial vehicle in a rockfall emergency scenario. Natural Hazards Earth System Sciences, 15, 163-169.

https://doi.org/10.5194/nhess-15-163-2015

[10] Francioni, M., Salvini, R., Stead, D., Giovannini, R., Riccucci, S., Vanneschi, C., \& Gullì, D. (2015). An integrated remote sensing-GIS approach for the analysis of an open pit in the Carrara marble district, Italy: Slope stability assessment through kinematic and numerical methods. Computers and Geotechnics, 67, 46-63. https://doi.org/10.1016/j.compgeo.2015.02.009

[11] Turner, D., Lucieer, A., \& De Jong, S. M. (2015). Time series analysis of landslide dynamics using an unmanned aerial vehicle (UAV). Remote Sensing, 7, 1736-1757. https://doi.org/10.3390/rs70201736

[12] Rinaudo, F., Chiabrando, F., Lingua, A. M., \& Spanò, A. (2012). Archaeological site monitoring: UAV photogrammetry can be an answer. ISPRS and Spatial Information Sciences - ISPRS Archives, 39, 583-588. https://doi.org/10.5194/isprsarchives-XXXIX-B5-583-2012

[13] Erenoğlu, R. C., Akçay, Ö., \& Erenoğlu, O. (2017). An uasassisted multi-sensor approach for 3D modeling and 
reconstruction of cultural heritage site. Journal of Cultural Heritage, 22, 1-21. https://doi.org/10.1016/j.culher.2017.02.007

[14] Nikolakopoulos, K. G., Soura, K., Koukouvelas, I. K., \& Argyropoulos, N. G. (2017). UAV vs classical aerial photogrammetry for archaeological studies. Journal of Archaeological Science: Reports, 14, 758-773. https://doi.org/10.1016/j.jasrep.2016.09.004

[15] Zhang, C. \& Kovacs, J. M. (2012). The application of small unmanned aerial systems for precision agriculture: a review. Precision Agriculture, 13, 693-712. https://doi.org/10.1007/s11119-012-9274-5

[16] Gomez, C. \& Purdie, H. (2016). UAV-based photogrammetry and geocomputing for hazards and disaster risk monitoring - a review. Geo. Dis., 3, 1-11. https://doi.org/10.1186/s40677-016-0060-y

[17] Giordan, D., Hayakawa, Y., Nex, F., Remondino, F., \& Tarolli, P. (2018) Review article: the use of remotely piloted aircraft systems (RPASs) for natural hazards monitoring and management. Natural Hazards Earth System Sciences, 18, 1079-1096. https://doi.org/10.5194/nhess-18-1079-2018

[18] Migoń, P. (2007). Granitoids in Poland. Archivum Mineralogiae Monograph 1. Geomorphology of granite terrains in Poland. London: Komitet Nauk Mineralogicznych PAN \& Wydział Geologii UW.

[19] Westoby, M. J., Brasington, J., Glasser, N. F., Hambrey, M. J., \& Reynolds, J. M. (2012). "Structure-from-Motion" photogrammetry: A low-cost, effective tool for geoscience applications. Geomorphology, 179, 300-314. https://doi.org/10.1016/j.geomorph.2012.08.021

[20] Kasprzak, M., Jancewicz, K., \& Michniewicz, A. (2018). $\mathrm{UAV}$ and SfM in detailed geomorphological mapping of granite tors: An example of Starościńskie Skały (Sudetes, SW Poland). Pure Appl. Geophys., 175, 3193-3207. https://doi.org/10.1007/s00024-017-1730-8

[21] Lyons-Baral, J. (2017). Geological analysis using UAV imagery and point clouds. GIS Resources, 4, 16-20.

[22] Nikolakopoulos, K., Kyriou, A., Koukouvelas, I., Zygouri, V., \& Apostolopoulos, D. (2019). Combination of aerial, satellite, and UAV photogrammetry for mapping the diachronic coastline evolution: The case of Lefkada Island. ISPRS International Journal of Geo-Information, 8, 489. https://doi.org/10.3390/ijgi8110489

[23] Lakshmi S. E. \& Yarrakula, K. (2018). Review and critical analysis on digital elevation models. Geofizika, 35(2), 129157. https://doi.org/10.15233/gfz.2018.35.7

[24] Mikrokopter (2019). Official Mikrokopter open source quadrotor homepage. Retrieved from http://www.mikrokopter.com (Accessed: 10.04.2019).

[25] Gjelsvik, T. (1956). Western Turkey Biga Peninsula in the Alpine Volcanism on mineral deposits linked searches. MTA Report, 2480.

[26] Dinçer, H. (1958). Preliminary report on the geological and economical aspect of Koru Mine. Located in the vicinity of Dardanelles in Turkey Owned by the Çanakkale Mining Company. Çanakkale Mining Report.

[27] Boikov, G. \& Jelev, D. (1992). About geological Researches, Maden in the Destricts of Ezine, Kocayayla, Koru Dere and others deposits about their prospective estimation. Çanakkale Mining Report.

[28] Robertson, D. \& Cipolla, R. (2009). Structure from Motion. Practical Image Processing and Computer Vision. John Wiley, Hoboken, NJ, USA.

[29] Henry, J. B., Malet, J. P., Maquaire, O., \& Grussenmeyer, P. (2002). The use of small-format and low-altitude aerial photos for the realization of high-resolution DEMs in mountainous areas: Application to the Super-Sauzeearthflow (Alpes-de-HauteProvence, France). Earth Surf. Processes and Landforms, 27(1), 1339-1350.

https://doi.org/10.1002/esp.411
[30] Hekimoglu, S., Erdogan, B., \& Erenoglu, R. C. (2015). A new outlier detection method considering outliers as model errors. Exp. Tech., 39, 57-68. https://doi.org/10.1111/j.1747-1567.2012.00876.x

[31] Lichti, D. D. (2005). Spectral Filtering and Classification of Terrestrial Laser Scanner Point Clouds. Pho. Rec., 20, 111, 218-240. https://doi.org/10.1111/j.1477-9730.2005.00321.x

[32] Eitelman, S. (2003). Matlab Version 6.5 Release 13. Ergonomics in Design, 11(3), 27-29.

\section{Contact information}

\section{Oya ERENOGLU}

Canakkale Onsekiz Mart University,

Faculty of Education, Department of Geography Education,

17100, Canakkale, Turkey

E-mail: o_turkdonmez@comu.edu.tr 